\title{
Is ICU admission associated with chronic narcotic use? a 4-year follow up of ICU survivors
}

\author{
PB Yaffe, MB Butler, RS Green, T Witter \\ From ESICM LIVES 2015 \\ Berlin, Germany. 3-7 October 2015
}

\begin{abstract}
Introduction
Patient comfort is a priority in the Intensive Care Unit (ICU). Narcotics are used to ensure optimal comfort and to facilitate patient management, including mechanical ventilation and other interventions. Previous studies indicate that chronic pain is common for an extended period after ICU discharge [1]. However, little data is available on the use of narcotic medications before and after ICU admission. We sought to describe narcotic use in this population over a multi-year time period.
\end{abstract}

\section{Objectives}

To describe narcotic use before and after ICU admission, and to identify factors associated with chronic narcotic use up to 4 years after ICU discharge.

\section{Methods}

Retrospective review of adult ( $\geq 18$ years) patients admitted to an ICU in Halifax, Canada between January 1, 2005 to December 31, 2008. The dataset was created by merging hospital databases with a provincial medication database. Data collected included age, gender, length of ICU/hospital stay, interventions and complications during admission. We defined "naïve", "intermittent", and "chronic" narcotic status by abstinence, use in $<70 \%$, or $>70 \%$ of days for a given time period, respectively. We assessed narcotic use at 3 months prior to ICU admission, at discharge, and annually for up to 4 years following ICU discharge.

Statistical methods used were Welch's t-test, Wilcoxon Rank-Sum test, Fisher's test, McNemar's test, and logistic regression.

\section{Results}

We included 2595 patients (mean age 46 yrs, 60.4\% male). Reason for ICU admission was surgical in $48.6 \%$, medical in $38.4 \%$ and undetermined in $13 \%$. The population included both elective and emergent admissions.

In the 3 months prior to ICU admission, 76.9\% were narcotic-naïve while $16.9 \%$ used narcotics intermittently, and $6.2 \%$ chronically. We found an increase in patients in the naïve category from $87.8 \%$ in the early post-ICU period to $95.6 \%$ at 48 -month follow-up with a corresponding decreasing trend in intermittent $(8.6 \%$ to $2.6 \%)$ and chronic (3.6\% to $1.8 \%)$ narcotic usage, respectively.

On logistic regression, prolonged hospital length of stay was associated with chronic narcotic use, although this effect varied with time. Naïve baseline narcotic use was associated with less chronic narcotic use, and intermittent baseline use was not associated with chronic use.

\section{Conclusions}

In our study, admission to an ICU was not associated with chronic narcotic use. Further research is required to confirm our findings in other health care environments.

\section{Grant Acknowledgment}

Support from Capital District Health Authority operating grant

Published: 1 October 2015

\footnotetext{
Reference

1. Devlin JW, Roberts RJ: Pharmacology of commonly used analgesics and sedatives in the ICU: Benzodiazepines, propofol,and opioids. Crit Care Clin 2009, 25(3):431-49.

doi:10.1186/2197-425X-3-S1-A366

Cite this article as: Yaffe et al:: Is ICU admission associated with chronic narcotic use? a 4-year follow up of ICU survivors. Intensive Care Medicine Experimental 2015 3(Suppl 1):A366.
} 